\title{
Analysis of Deformation in Ni-Cr Structures with New and Recast Alloys
}

\author{
Humberto Gennari Filho, Marcelo Coelho Goiato, José Vitor Quinelli Mazaro, \\ Karina Helga Leal Túrcio \\ State Paulista University, São Paulo, Brazil \\ Email: gennari@foa.unesp.br
}

Received 10 May 2015; accepted 28 July 2015; published 31 July 2015

Copyright (C) 2015 by author and Scientific Research Publishing Inc. This work is licensed under the Creative Commons Attribution International License (CC BY). http://creativecommons.org/licenses/by/4.0/

(c) (i) Open Access

\begin{abstract}
The present study analyzed new and recast $\mathrm{Ni}$-Cr alloys, regarding the relationship between the applied force and the deformation in cantilevered bar segments, with dimensions of $4.0 \mathrm{~mm}, 3.5$ $\mathrm{mm}, 3.0 \mathrm{~mm}$ in thickness, $4.5 \mathrm{~mm}$ width and $15 \mathrm{~mm}$ length, on a universal testing machine "EMIC". The bars in the tests were initially obtained acrylic resin by $4.8 \mathrm{~mm}$ wide $\times 4.3 \mathrm{~mm}$ thick $\times 4 \mathrm{~cm}$ long. We obtained 30 bars divided into two groups, with 15 to test new alloys and 15 with alloys recast. The alloy used was Tilite. For the application of the load, the bars were attached to "EMIC" where the active tip of $200 \mathrm{kgf}$ load cell was at a specific point of the bar $(15 \mathrm{~mm})$ with a speed of $0.5 \mathrm{~mm}$ per minute. The data showed statistically significant differences in relation to alloys and thickness among the bars, and all thicknesses evaluated were different. Thus, it was concluded that there was statistically significant difference between the groups and their variables, and that the alloys recast could be reused at least 1 time, without loss of properties.
\end{abstract}

\section{Keywords}

Alloys, Oral Protheses, Dental Materials

\section{Introduction}

The implantology became popular due to the clinical studies that were very well conducted by Branemark and co-workers, who gave a scientific basis to implant prosthodontics. Until then, little had been said or known about the implantations and a few patients could take advantage of this treatment. Due to reports of success based on researches that supported this type of therapy, its diffusion had created a new space for the prosthesis, setting new expectations, especially for edentulous. However, the recovery of the edentulous arch by implantation remained restricted to the anterior region, limited by the mentual foramen, which made impossible the ex- 
tension of prosthesis to the posterior region, due to the proximity of the mentual canal to the residual alveolar crest. Certainly, the objective was to extend the prosthesis up to the posterior limits in order not to promote mucosal support and thereby did not increase the resorption of bone tissue [1] [2].

Therefore, new concepts have been revised based on beams engineering principles, allowing the prosthesis to be immobilized by the implants and distally extended by bilateral bars segments named "cantilever" [3]. Cantilever is a bar segment with one of the tips attached to a pillar while the other remains suspended [3]. In this context, it creates a class I lever system, which dramatically alters the direction and magnitude of the forces on the distal tooth or implant. Stewart and Staab [4] [5] mention that the cantilever implant supported structures can be adversely affected in situations where there is a decreased intermaxillary space, excessive length of the cantilever or in patients with parafunctional habits. To characterize the fatigue behavior of structures with cantilevered fixed implant-supported prostheses requires an understanding of the material and its application, and relations among the applied load, the component geometry and fatigue characteristics of a specific material [4] [6].

The economic aspect should not be the justification to the use of non-noble metals. The alloys must have physical, chemical, mechanical and biological properties that justify their indication as efficient restorative materials so that they can be viable alternatives. However, some prosthodontic laboratories have reused leftovers of castings to manufacture new pieces in order to make the final cost even less. This attitude was assessed by some authors, who considered it as a real possibility [7] [8].

There are no studies that prove the effectiveness and reliability of this technique. Thus, the present study analyzed new and recast $\mathrm{Ni}-\mathrm{Cr}$ alloys, regarding the relationship between the applied force and the deformation in cantilevered bar segments, with dimensions of $4.0 \mathrm{~mm}, 3.5 \mathrm{~mm}, 3.0 \mathrm{~mm}$ in thickness, $4.5 \mathrm{~mm}$ width and $15 \mathrm{~mm}$ length, on a universal testing machine.

\section{Material and Method}

Initially, bars of acrylic resin were obtained using a steel frame $8 \mathrm{~cm}$ length $\times 4.8 \mathrm{~mm}$ width $\times 4.3 \mathrm{~mm}$ in thickness, worn and controlled by a MAUb caliper. Each bar was sectioned in the middle originating two bars with 4 $\mathrm{cm}$, ready for casting. Thus 30 bars were obtained and divided into two groups with 15 bars to test new alloys (NA) and 15 to test recast alloys (RA) (Figure 1).

The alloy used was "Tilite" (Talladium do Brasil-Curitiba, PR) based on nickel-chromium-molybdenum-titanium, which is suitable for metal ceramic classic fixed prostheses and for implants prosthodontics structures; the lining was "Micro-fine 1700" (Talladium do Brasil-Curitiba, PR).

For compression loading, the bars were trapped in a bench vise built specifically for this research and tied to Universal Testing Machine "EMIC" by screws that allowed the free movement of the joint. Therewith, the active tip of EMIC could apply a 200-kgf load, $0.5 \mathrm{~mm}$ per minute, at a specific point of the bar (15 mm) (Figure 2).

After activated, the machine automatically and gradually increased the load until the point of fatigue in the alloy, which was monitored by a computer program, showing on the computer screen through graph 1 (Figure $3)$, the relation between the applied force and the deformation.

Thus, the bars with different thicknesses and types of alloys (new and recast) were submitted to the test, considering the load application in a $15-\mathrm{mm}$ cantilever.

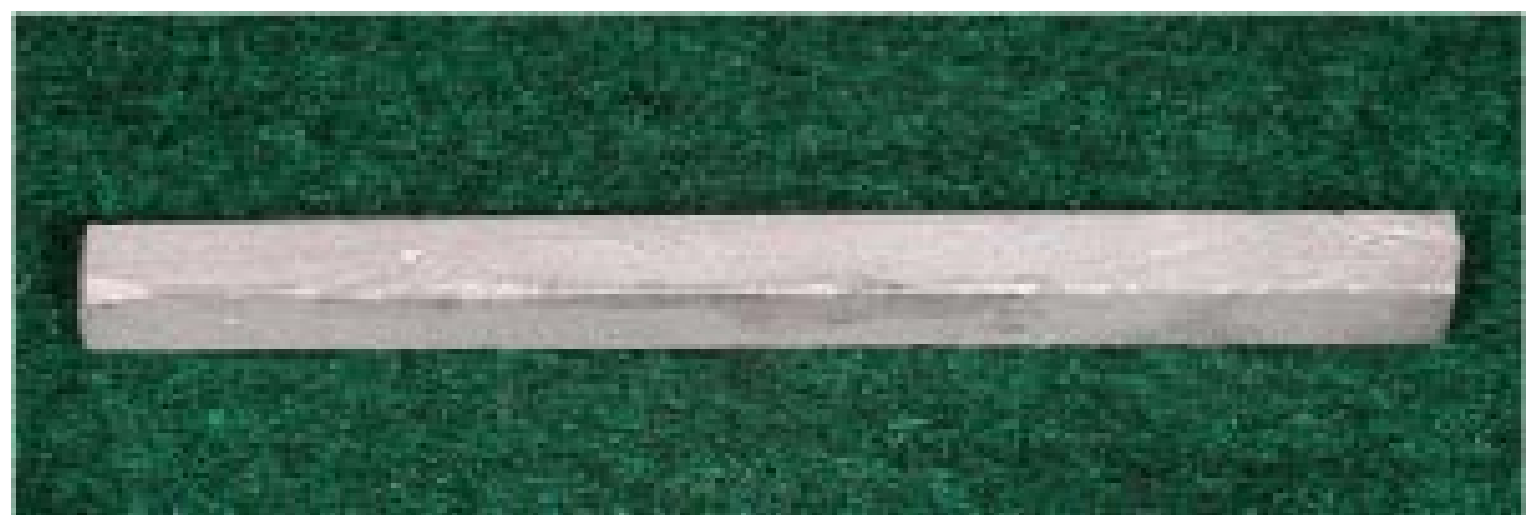

Figure 1. Complete bar to be subjected to compressive loading (experimental sample). 


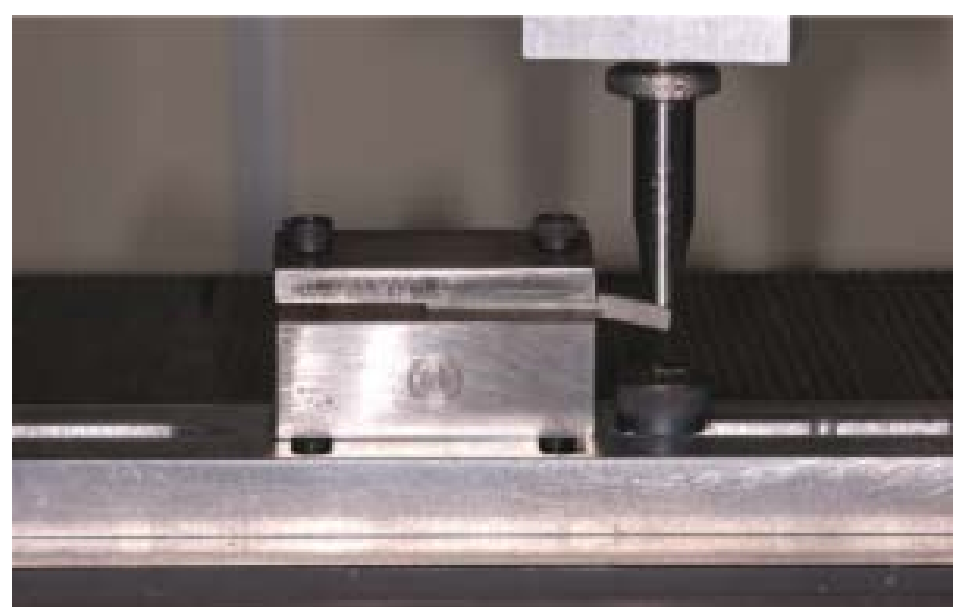

Figure 2. Cast bar and secured in a vise with the application load testing machine (bar deformed by the action of the force).

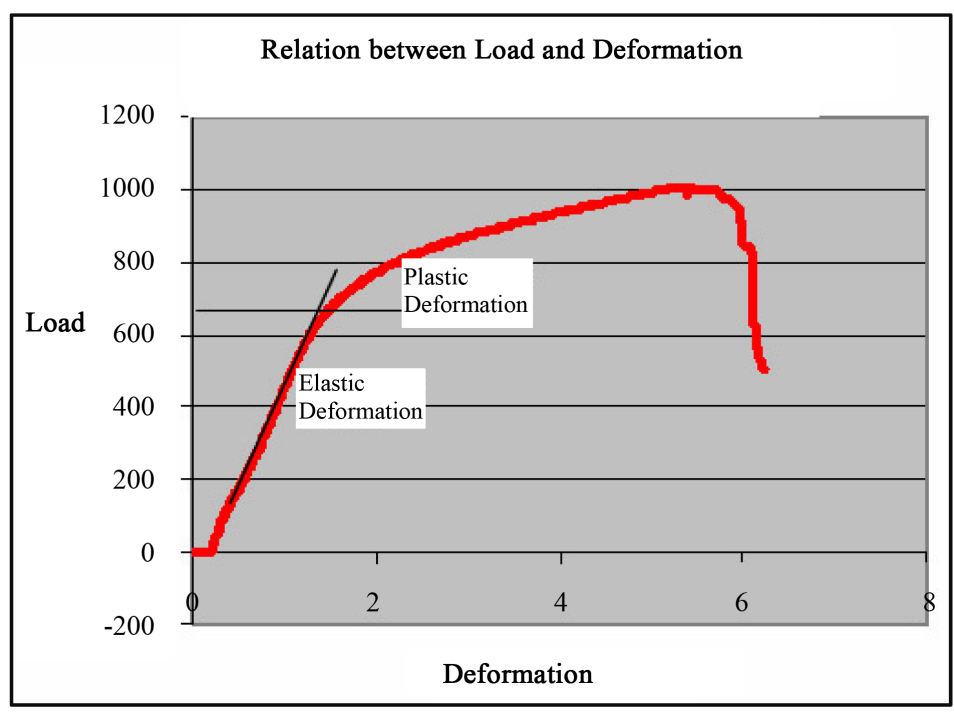

Figure 3. Yield representation of the alloy showing the phases of elastic deformation and plastic (experimental sample).

\section{Results}

Table 1 presents the representative yielding values of each specimen cast in new alloy (Ni-Cr). The specimens were submitted to constant load in three thicknesses proposed in the study. For each thickness, five specimens were analyzed, which values established a representative mean of the conjunct, used for comparison purposes.

Table 2 shows the yielding values correspondent to the samples made of recast Ni-Cr alloy, which underwent constant load. It may be noted that as the thickness of the bars increased, the values of the specimens also increased.

However, when comparing the final averages in both situations with the same thicknesses, it is observed that the specimens made of recast alloy present higher values than those cast with new alloy. This implies that the plastic deformation point of the recast alloy was higher than the new alloy, excepting the $4.5 \times 3.0$ thicknesses, which can clearly be observed in Figure 4.

Thus, based on the values presented it can be said that the recast alloy exhibited plastic deformation $4.9 \%$ below new alloy for bars with dimensions of $4.5 \times 3.0 \mathrm{~mm} ; 16.9 \%$ above the bars with $4.5 \times 3.5 \mathrm{~mm}$ and $6.3 \%$ higher for the bars with $4.5 \times 4.0 \mathrm{~mm}$.

Statistical analysis was performed with data distribution considered normal and parametric tests were applied. 
Table 1. Values and means of disposing of bodies of evidence regarding new alloys, in various thicknesses.

\begin{tabular}{ccccccc}
\hline & \multicolumn{5}{c}{ Means of new alloys (NA) } \\
\hline Thickness & CP 1 & CP 2 & CP 3 & CP 4 & CP 5 & Means \\
\hline $4.5 \times 3.0$ & 620.2 & 624.8 & 617.07 & 618.38 & 643.58 & 624.8 \\
$4.5 \times 3.5$ & 678.1 & 638.26 & 724.02 & 678.07 & 646.57 & 673 \\
$4.5 \times 4.0$ & 1099.9 & 942.64 & 846.65 & 968.35 & 838.7 & 939.24 \\
\hline
\end{tabular}

Table 2. Values and means of disposing of bodies of evidence regarding alloy remelted in various thickness.

\begin{tabular}{ccccccc}
\hline & \multicolumn{5}{c}{ Means of recast alloys (RA) } \\
\hline Thickness & CP 1 & CP 2 & CP 3 & CP 4 & CP 5 & Means \\
\hline $4.5 \times 3.0$ & 629.42 & 609.47 & 619.08 & 586.03 & 525.08 & 593.85 \\
$4.5 \times 3.5$ & 770.86 & 743.76 & 830.27 & 840.2 & 868.81 & 810.78 \\
$4.5 \times 4.0$ & 978.32 & 1019.33 & 1042.3 & 980.21 & 995.46 & 1003.12 \\
\hline
\end{tabular}

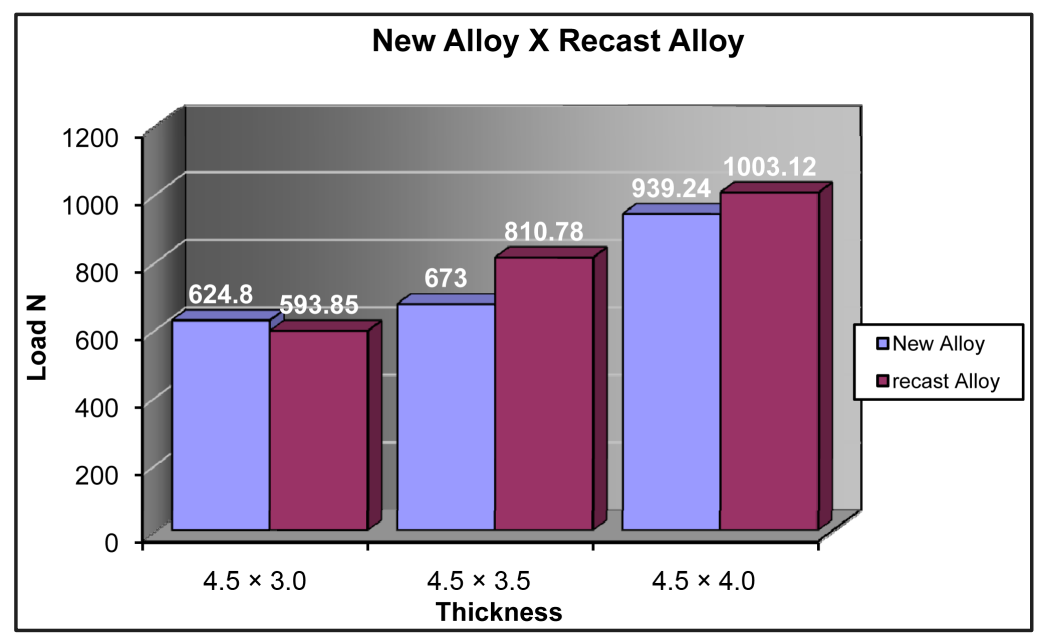

Figure 4. Representation of point values of plastic deformation of the $\mathrm{Ni}-\mathrm{Cr}$ alloy remelted in new and different thicknesses.

Results were submitted to analysis of variance for two factors of variation (cast and recast alloys and thickness of the bars) complemented by the Tukey test. Considering $\mathrm{p}<0.05$, data demonstrated statistically significant differences in relation to cast and recast alloys $(\mathrm{p}=0.00420)$. Among the thicknesses of the bars, there were also statistically significant differences $(p=0.0000)$, whereas all the thicknesses were different from each other.

\section{Discussion}

Despite negative arguments, the cantilever has been widely used by clinicians. If used indiscriminately without following appropriate guidelines, the cantilever may lead to some complications, such as failures in extensive oral rehabilitation. The arrangement of pillars and pontics also represents a major drawback: the creation of a class I lever system. When the cantilevered pontic is placed under occlusal function, forces are applied on the pillars [9] [10].

There are several criteria and factors necessary for success in cantilevered fixed prostheses-the alloys used for fabrication of cantilever bars must present good quality and laboratory casting technique must be properly executed so that potential failures, such as rupture and distortion do not occur. Some of metallurgical properties that influence the clinical performance of the alloys are: grain size, the phase structure, elasticity, hardness, elastic modulus, color, corrosion and biocompatibility. The composition plays an important role in influencing the properties mentioned above. Besides cost, these factors become more critical when the alloy is recycled or 
reused.

However, based on their clinical applicability, the moment of rupture or fatigue of the alloys is not a concern, because at this stage the entire structure will be lost. On the other hand, the "moment of transition" in which they undergo an irreversible deformation by the action of the applied force, is very important. Thus, the most representative point is the yielding, which represents the transition from elastic deformation to plastic deformation of the alloy. Above a given stress, known as the elastic limit or yield limit, the relationship between stress and deformation is broken and the solid can be deformed irreversibly, exhibiting a plastic behavior. The beginning of plastic deformation normally means the collapse of a structure [11].

According to Nathanson [12], one of the main characteristics of a brittle material is the lack of a plastic behavior and an inability to withstand deformation when subjected to stress. Based on information provided by Talladium, manufacturer of the alloy used in this study, states that when it is recast respecting the rules, changes such as loss of castability, increased rate of corrosion, tensile strength and modulus of elasticity, are not observed in their chemical and physical properties, as it occurs in non-noble metal alloys.

However, it is known that adding a small percentage of a certain material to an alloy changes its mechanical properties resulting in divergent data. In order to change its properties and ensure quality, new metals, such as Ti, $\mathrm{Mo}, \mathrm{Be}, \mathrm{Al}, \mathrm{Fe}$ and $\mathrm{Sn}$ can be added to the Ni-Cr alloy [13].

Thereby, the recasting allows reusing the alloy at least once, without altering their properties so that it makes impossible its use as extended cantilevered bar. From an economic standpoint, it is a factor to be taken into consideration because the casting leftovers can be used enabling the prosthesis to be submitted to the chewing forces [11] [14].

\section{Conclusions}

After analyzing the obtained data and applying statistical tests, it can be concluded that:

- There is statistical significant difference between the new and recast alloys and among the thicknesses of the bars;

- The values of elastic deformation are higher for the recast alloys in the $4.5 \times 3.5$ and $4.5 \times 4.0$ thicknesses and below for $4.5 \times 3.0$ thickness;

- The recast alloys can be reused at least once, without losing their properties.

\section{Acknowledgements}

FUNDUNESP-Institution UNESP.

\section{References}

[1] Zarb, G.A., Jansson, T. and Jemt, T. (1985) Other Prosthodontic Applications. In Branemark, P.I., Zarb, G.A. and Albrektsson, T., Eds., Tissue Integrated Prostheses: Osseointegration in Clinical Dentistry, Quintessence, Chicago, $283-$ 287.

[2] Smyd, E.S. (1952) Mechanics of Dental Structures: Guide to Teaching Dental Engineering at Undergraduate Level. Journal of Prosthetic Dentistry, 2, 668-693. http://dx.doi.org/10.1016/S0022-3913(52)80045-9

[3] Rodrigues, A.M., Aquilino, S.A., Lund, P.S., Ryther, J.S. and Southard, T.E. (1993) Evaluation of Strain at the Terminal Abutment Site of a Fixed Mandibular Implant Prosthesis during Cantilever Loading. Journal of Prosthodontics, 2, 93-102. http://dx.doi.org/10.1111/j.1532-849X.1993.tb00389.x

[4] Stewart, R.B. and Staab, G.H. (1995) Cross-Sectional Design and Fatigue Durability of Catilevered Sections of Fixed Implant-Supported Prostheses. Journal of Prosthodontics, 4, 188-194. http://dx.doi.org/10.1111/j.1532-849X.1995.tb00339.x

[5] Staab, G.H. and Stewart, R.B. (1994) Theoretical Assessment of Cross-Section for Cantilevered Implant-Supported Prostheses. Journal of Prosthodontics, 3, 23-30. http://dx.doi.org/10.1111/j.1532-849X.1994.tb00121.X

[6] Gallucci, G.O., Doughtied, C.B., Hwangh, J.W., Fiorellini, J.P. and Weber, H.P. (2009) Five-Year Results of Fixed Implant Supported Rehabilitations with Distal Cantilevers for the Edentulous Mandible. Clinical Oral Implants Research, 20, 601-607.

[7] Fernandes, D.R. (2005) Influence of Remelting of an Alloy of Ni-Cr Cervical Adaptation and Internal Crowns with Different Configurations. Ph.D. Thesis, Piracicaba School of Dentistry, State University of Campinas, Campinas.

[8] Vilar, C.D. (2008) Influence of the Number of Recast Alloy Cr-Ni-Ti-M0 on the Properties of Metal-Ceramic Prosthe- 
sis. Ph.D. Thesis, Universidade Federal do Rio Grande do Norte, Natal.

[9] Aglieta, M., Siciliano, V.I., Zwhlen, M., Bragger, U., Pjetursson, B.E., Lang, N.P. and Salvi, G.E. (2009) A Systematic Review of the Survival and Complication Rates of Implant Supported Fixed Dental Prostheses with Cantilever Extensions after an Observation Period of at Least 5 Years. Clinical Oral Implants Research, 20, 441-451. http://dx.doi.org/10.1111/j.1600-0501.2009.01706.x

[10] Mc Alarney, M.E. and Stavropoulos, D.N. (2000) Theoretical Cantilever Lengths versus Clinical Variables in FiftyFive Clinical Cases. Journal of Prosthetic Dentistry, 83, 332-343. http://dx.doi.org/10.1016/S0022-3913(00)70137-5

[11] Huang, H.H., Lin, M.C., Lee, T.H., Yang, H.W., Chen, F.L., Wu, S.C. and Hsu, C.C. (2005) Effect of Chemical Composition of Ni-Cr Dental Casting Alloys on the Bonding Characterization between Porcelain and Metal. Journal of Oral Rehabilitation, 32, 206-212. http://dx.doi.org/10.1111/j.1365-2842.2004.01411.x

[12] Nathanson, D. (1996) Principles of Use Porcelain as a Material for Inlay/Onlay. In: Garber, D.A. and Goldstein, R.E., Eds., Inlays and Onlays, Porcelain and Composite Resin, Quintessence, Chicago.

[13] Kumar, N.S. and Chandra, T.S. (2008) Evaluation of Variations in Composition, Corrosion Behavior and Surface Hardness on Reusing a Co-Cr-Mo Denture Alloy. The Journal of Indian Prosthodontic Society, 8, 22-26. http://dx.doi.org/10.4103/0972-4052.43249

[14] Mirković, N. (2007) Effect of Recasting on the Elastic Modulus of Metal-Ceramic Systems from Nickel-Chromium and Cobalt-Chromium Alloys. Vojnosanitetski Pregled, 64, 469-473. http://dx.doi.org/10.2298/VSP0707469M 